\title{
- Original-
}

\section{Effect of Adjuvant Transarterial Infusion of Anticancer Agents after Transurethral Resection in Patients with pT2a Muscle Invasive Transitional Cell Carcinoma of the Bladder: Five and Ten-year Outcome}

\author{
Hiroyuki Shimizu, Taiji Nishimura, Go Kimura, \\ Ichiro Matsuzawa and Yukihiro Kondo \\ Department of Urology, Nippon Medical School
}

\begin{abstract}
Five- and ten-year survival rates in patients who had transurethral resection for pT2aN0M0 muscle invasive transitional cell carcinoma of the bladder was studied with emphasis on the effect of adjuvant transarterial infusions of anticancer agents (TAI). A total of 17 patients out of 290 patients with bladder cancer who had initial treatment in our department between January 1991 and May 2001 were found to be pT2aNOM0 and were included in the present study. Fifteen patients received intravesical instillations of BCG after transurethral resection of the bladder tumor and 8 patients received TAI which was given two weeks after bacillus Calmette-Guerin therapy, with the exception of 1 patient. Five- and ten-year overall survival rates were $76.0 \%$ and $52.1 \%$, respectively, and both five- and ten-year cancer-specific survival rates were $76.0 \%$ with an average follow up of 71 months. Significant prognostic factor associated with survival rates was only the infiltration pattern of the tumor cells between the alpha and beta group and gamma group $(\mathrm{P}=0.0420)$ in cancer-specific survival rates. The data support conservative management of transurethral resection followed by intravesical instillation of BCG and TAI in patients with pT2a bladder cancer.
\end{abstract}

(J Nippon Med Sch 2004; 71: 263-269)

Key words: transurethral resection, invasive bladder cancer, intravesical instillation, chemotherapy

\section{Introduction}

Considerable disagreement remains regarding the proper treatment of vesical neoplasms. For instance, most urologists choose cystectomy with or without chemotherapy and radiotherapy for patients with muscle-infiltrating bladder cancer; however several reports recommend conservative management with transurethral resection of the bladder tumor (TURBT) $)^{1-6}$.

Our policy is to perform transurethral resection (TUR) followed by intravesical instillation of bacillus Calmette-Guerin (BCG) and transarterial infusion of anticancer agents (TAI) in patients with pT2a muscle invasive transitional cell carcinoma (TCC) of

Correspondence to Taiji Nishimura, Department of Urology, Nippon Medical School, 1-1-5 Sendagi, Bunkyo-ku,

Tokyo 113-8603, Japan

Journal Website (http://www.nms.ac.jp/jnms/) 
Table 1 Patient characteristics

\begin{tabular}{|c|c|c|c|}
\hline Variables & $\begin{array}{c}\text { Total } \\
\text { Patients }\end{array}$ & $\begin{array}{l}\text { Patients who } \\
\text { died of BT }\end{array}$ & $\begin{array}{l}\text { Other } \\
\text { Patients }\end{array}$ \\
\hline Mean age (yrs.) & 71.5 & 77.3 & 69.7 \\
\hline \multicolumn{4}{|l|}{ Gender } \\
\hline Male & $14(82.4)$ & 3 & 11 \\
\hline Female & $3(17.6)$ & 1 & 2 \\
\hline \multicolumn{4}{|l|}{ Grade } \\
\hline 2 & $10(58.8)$ & 2 & 8 \\
\hline 3 & $7(41.2)$ & 2 & 5 \\
\hline \multicolumn{4}{|l|}{ INF } \\
\hline$\alpha$ & $3(17.6)$ & 1 & 2 \\
\hline$\beta$ & $8(47.1)$ & 0 & 8 \\
\hline$\gamma$ & $6(35.3)$ & 3 & 3 \\
\hline \multicolumn{4}{|c|}{ Maximum tumor size } \\
\hline$<3 \mathrm{~cm}$ & $6(35.3)$ & 2 & 4 \\
\hline$\geqq 3 \mathrm{~cm}$ & $11(64.7)$ & 2 & 9 \\
\hline \multicolumn{4}{|l|}{ No. tumors } \\
\hline Single & $7(41.2)$ & 2 & 5 \\
\hline Multiple & $10(58.8)$ & 2 & 8 \\
\hline \multicolumn{4}{|l|}{ Concomitant CIS } \\
\hline Positive & $3(17.6)$ & 1 & 2 \\
\hline Negative & $14(82.4)$ & 3 & 11 \\
\hline \multicolumn{4}{|l|}{ BCG } \\
\hline Performed & $15(88.2)$ & 3 & 12 \\
\hline Not performed & $2(11.8)$ & 1 & 1 \\
\hline \multicolumn{4}{|l|}{ TAI } \\
\hline Performed & $7(41.2)$ & 1 & 6 \\
\hline Not performed & $10(58.8)$ & 3 & 7 \\
\hline
\end{tabular}

BT; bladder tumor. INF: infiltration pattern of tumor cells. CIS: carcinoma in situ. BCG: Bacillus Calmette-Guerin, TAI: Transarterial infusion of anticancer agents. Numbers in parentheses are percentages.

the bladder. Usefulness of intravesical instillation of BCG in patients with T2a TCC has been reported recently ${ }^{6}$ and advantage of TAI in invasive bladder cancer including pT2aN0M0 TCC has been reported mainly by Japanese researchers ${ }^{7.8}$.

In the present study, we have evaluated five and ten-year survival rates in patients with pT2a bladder cancer who were treated with the aforementioned method with emphasis on the effect of adjuvant TAI.

Although the sample size was small, at $n=17$, we believe it is worth reporting due to the limited literature available in this area. Of additional value was the lengthy follow up period (71 months) and the lack of patients who were lost to follow up in our series.

\section{Material and Methods}

A total of 17 patients out of 290 patients with bladder cancer who had initial treatment in our department between January 1991 and May 2001 were found to have pT2aN0M0 by initial TUR. The median age of these patients was 71.5 (range: 60 86). Patient characteristics are summarized in Table 1. Staging and characteristics of each tumor was done according to TNM classification and the World Health Organization system. A pT2a is defined as tumor cells which extend into the superficial half of the detrusor muscle. Staging of pT2a was confirmed by following methods: 1) The tumor was resected by a pure cut to minimize tissue damage due to electric current such that the entire or part of the tumor and the muscle layer were included in a single piece, 
2) One or two specimens obtained by additional resection of the muscle layer beneath the tumor were step wisely pierced by a 23 gage injection needle and sent for pathological examination ${ }^{7.8}$. Staging for lymph nodes and distant metastasis was performed by computed tomography (CT).

Intravesical instillations of $120 \mathrm{mg}$ BCG in $50 \mathrm{ml}$ saline starting 7 to 14 days after the initial resection of the bladder tumor were performed weekly for 6 weeks. No maintenance therapy was given. Two weeks after BCG therapy, TAI was performed when patient accepted the therapy upon our recommendation. Anticancer agents in TAI consisted of Cisplatin (CDDP) $100 \mathrm{mg} / \mathrm{m}^{2}$, Methotrexate (MTX) $30 \mathrm{mg} / \mathrm{m}^{2}$ and Doxorubicin (ADR) $20 \mathrm{mg} /$ body. The tip of the transarterial catheter was sent just above the bifurcation of the abdominal aorta. Embolization of the bilateral superior gluteal artery and bilateral thigh tourniquets were routinely performed to prevent necrosis of the gluteal and thigh muscles and to increase the concentration of anticancer agents in the vessels of the pelvis. Our protocol consisted of two courses of TAI after initial TURBT, TUR biopsy of the bladder followed by two courses of TAI. Intravenous chemotherapy instead of TAI with CDDP $100 \mathrm{mg} / \mathrm{m}^{2}$, MTX $60 \mathrm{mg} / \mathrm{m}^{2}$ and vinblastine (VBL) $12 \mathrm{mg} / \mathrm{m}^{2}$ (CMV) in total dose was performed in 1 patient.

After TURBT; cystoscopy, urinary cytological examination and soluble cytokeratin 19 fragments in serum and urine ${ }^{11}$ was performed every 3 months for 3 years, every 6 months from 3 to 5 years, and annually after 5 years. Intravenous pyelography was performed every 6 months for 3 years, and annually after 3 years. Chest radiographs and pelvic CT were performed every 6 months for 3 years, and annually after 3 years. In cases with visible tumor lesions or hyperemic mucosal findings in the bladder by cystoscopy, positive urinary cytological findings or markedly elevated serum or urine CYFRA 21-1, transurethral biopsy was performed to detect recurrent diseases.

Five and ten-year overall survival rates and cancer-specific survival rates were calculated using the Kaplan-Meier method, and differences were evaluated by the log-rank test. Probability values less than $\mathrm{P}=0.05$ were considered significant.

\section{Results}

The characteristics of patient treatment and prognosis are summarized in Table 2.

Of 17 patients analyzed in this series, the average follow up period was 71 months (range, 8 139 months, median 73 months). Fifteen patients (3 deceased patients with bladder cancer and 12 others) received intravesical instillations of BCG. TAI was performed in 8 patients (1 deceased patients with bladder cancer and 7 others) who accepted TAI, while other 9 patients did not want to have the therapy. TAI was performed upon recurrence without performing TAI at the time of initial TURBT in 2 patients (Cases 1 and 3), although BCG therapy was performed in both cases. Intravenous chemotherapy with CMV was performed immediately after initial TURBT without BCG therapy in other 1 patient (Case 2).

None of patients were lost to follow up. 4 patients died due to bladder tumor recurrence and 2 patients died without evidence of bladder cancer. The causes of death were primary lung cancer and acute myocardial infarction, respectively. The other 11 patients survived without evidence of bladder tumor recurrence upon the last examination. The median interval between intravesical recurrence and initial TURBT in the 4 deceased patients who died due to bladder tumor recurrence was 5.75 months (range: $4 \sim 8$ months), whereas that in 4 of the 13 other patients was 12.25 months (range: $6 \sim 21$ months). Methods of treatment after recurrence in each case were follows: Case 1: TURBT followed by chemotherapy with a total dose of $375 \mathrm{mg}$ CDDP; Case 2: TURBT followed by cystectomy and radiation; Case 3: TURBT followed by TAI with 240 $\mathrm{mg}$ of CDDP, $75 \mathrm{mg}$ of MTX and $60 \mathrm{mg}$ of ADR; Case 4:TURBT followed by TAI with $80 \mathrm{mg}$ of CDDP $80 \mathrm{mg}, 25 \mathrm{mg}$ of MTX and $30 \mathrm{mg}$ of ADR; Case 9: TURBT and cystectomy; Case 10: TURBT three times followed by BCG twice; Case 11: TURBT; Case 17: TURBT twice.

The cystectomy followed by radiation in Case 2 
Table 2 Characteristics of patients and methods of treatment classified by prognosis

\begin{tabular}{|c|c|c|c|c|c|c|c|c|c|c|c|c|}
\hline \multirow{2}{*}{$\begin{array}{c}\text { Case } \\
\text { no. }\end{array}$} & \multirow{2}{*}{$\begin{array}{l}\text { Age } \\
\text { (yrs) }\end{array}$} & \multirow[b]{2}{*}{ Sex } & \multicolumn{2}{|c|}{ Tumor } & \multirow{2}{*}{$\begin{array}{l}\text { Tumor } \\
\text { Grade }\end{array}$} & \multirow[b]{2}{*}{ INF } & \multirow{2}{*}{$\begin{array}{l}\text { Concomitant } \\
\text { CIS }\end{array}$} & \multirow{2}{*}{$\begin{array}{l}\text { BCG } \\
\text { after } \\
\text { initial }\end{array}$} & \multirow{2}{*}{$\begin{array}{l}\text { TAI } \\
\text { TUR }\end{array}$} & \multirow{2}{*}{$\begin{array}{l}\text { Months } \\
\text { before } \\
\text { first } \\
\text { recurrence }\end{array}$} & \multirow{2}{*}{$\begin{array}{l}\text { Number of } \\
\text { recurrence }\end{array}$} & \multirow[b]{2}{*}{ Cystectomy } \\
\hline & & & no. & $\begin{array}{l}\text { size } \\
(\mathrm{cm})\end{array}$ & & & & & & & & \\
\hline & \multicolumn{12}{|c|}{ died with bladder cancer } \\
\hline 1 & 73 & $\mathrm{~F}$ & 1 & 1 & 3 & $\gamma$ & - & + & - & 5 & 2 & - \\
\hline 2 & 72 & M & 1 & 4 & 3 & $\gamma$ & - & - & - & 4 & 1 & + \\
\hline 3 & 86 & M & 2 & 2 & 2 & $\alpha$ & - & + & - & 6 & 1 & - \\
\hline 4 & 78 & M & 4 & $>3$ & 2 & $\gamma$ & + & + & + & 8 & 1 & - \\
\hline \multicolumn{13}{|c|}{ died with other disease } \\
\hline 5 & 68 & M & 4 & 4 & 2 & $\beta$ & - & + & - & - & - & - \\
\hline 6 & 67 & M & 6 & 2 & 3 & $\beta$ & + & + & - & - & - & - \\
\hline \multicolumn{13}{|c|}{ alive without bladder cancer } \\
\hline 7 & 71 & M & 4 & 4 & 3 & $\gamma$ & - & + & + & - & - & - \\
\hline 8 & 72 & $\mathrm{~F}$ & 1 & 4 & 2 & $\beta$ & - & + & - & - & - & - \\
\hline 9 & 72 & M & 1 & 3 & 2 & $\alpha$ & - & - & + & 21 & 1 & + \\
\hline 10 & 66 & M & 4 & 2 & 2 & $\beta$ & - & + & - & 6 & 3 & - \\
\hline 11 & 74 & M & 2 & 2.5 & 2 & $\beta$ & - & + & - & - & - & - \\
\hline 12 & 60 & $\mathrm{M}$ & 2 & 3 & 2 & $\alpha$ & - & + & + & 11 & 1 & - \\
\hline 13 & 70 & $\mathrm{M}$ & 1 & $<3$ & 3 & $\beta$ & + & + & + & - & - & - \\
\hline 14 & 71 & $\mathrm{M}$ & 2 & 4 & 2 & $\beta$ & - & + & + & - & - & - \\
\hline 15 & 67 & $\mathrm{M}$ & 1 & 3 & 2 & $\beta$ & - & + & + & - & - & - \\
\hline 16 & 77 & $\mathrm{M}$ & 1 & 3 & 3 & $\gamma$ & - & + & - & - & - & - \\
\hline 17 & 72 & $\mathrm{~F}$ & 2 & 3 & 3 & $\gamma$ & - & + & + & 11 & 2 & - \\
\hline
\end{tabular}

F: female, M: male, INF: infiltration pattern of tumor cells. CIS: carcinoma in situ. BT; bladder tumor. BCG: Bacillus Calmette-Guerin, TAI: Transarterial infusion of anticancer agents.

was also performed in 1 expired patient 4 months after TURBT and adjuvant therapy with intravenous chemotherapy with CMV due to suspected lymph node metastasis in the pelvis.

The cystectomy in Case 9 was performed at the national hospital of patient's hometown 2 years after initial TURBT because punch biopsy revealed G2, TCC. However, pathological examination of the removed bladder revealed only CIS and the patient remains alive 139 months after the cystectomy without evidence of disease recurrence.

The bladder was preserved in 15 of the 17 patients $(88.2 \%)$.

Five and ten-year overall survival rates were $76.0 \%$ and $52.1 \%$ (Fig. 1 upper), respectively, and both five and ten-year cancer-specific survival rates were $76.0 \%$ with an average follow up of 71 months (Fig. 1 lower).

The five and ten-year overall survival rates as well as cancer-specific survival rates did not significantly differ according to tumor size, tumor number, tumor grade, concomitant CIS and
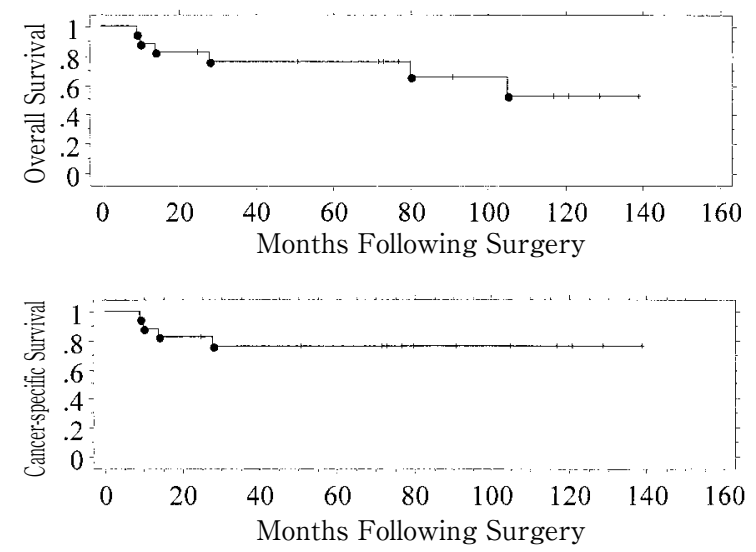

Fig. 1 Five and ten-year overall survival rates (upper) and cancer-specific survival rates (lower).

treatment with BCG and TAI. However, there was tendency for the five and ten-year overall survival rates, as well as cancer-specific survival rates, in patients who had TAI after initial TURBT to be higher than those in patients who did not have TAI after initial TURBT (Fig. 2). The five-year overall survival rates in the former and the latter were 

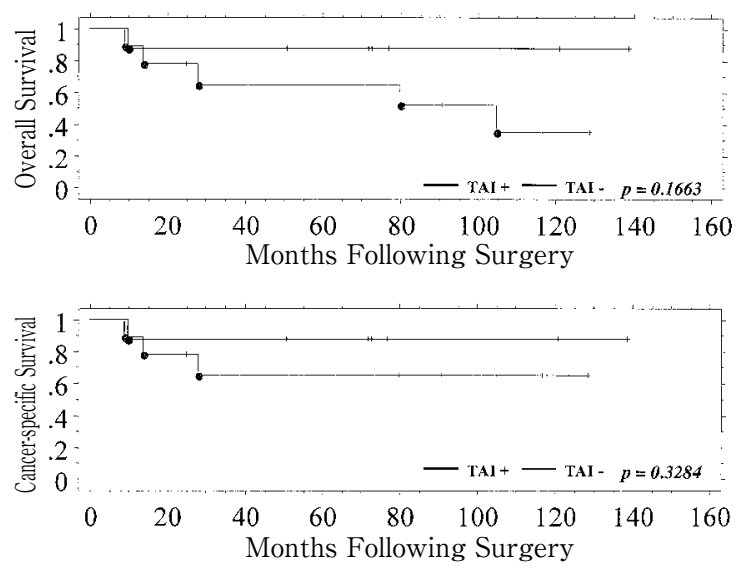

Fig. 2 Five and ten-year overall survival rates (upper) and cancer-specific survival rates (lower), in patients with or without TAI after initial TURBT.
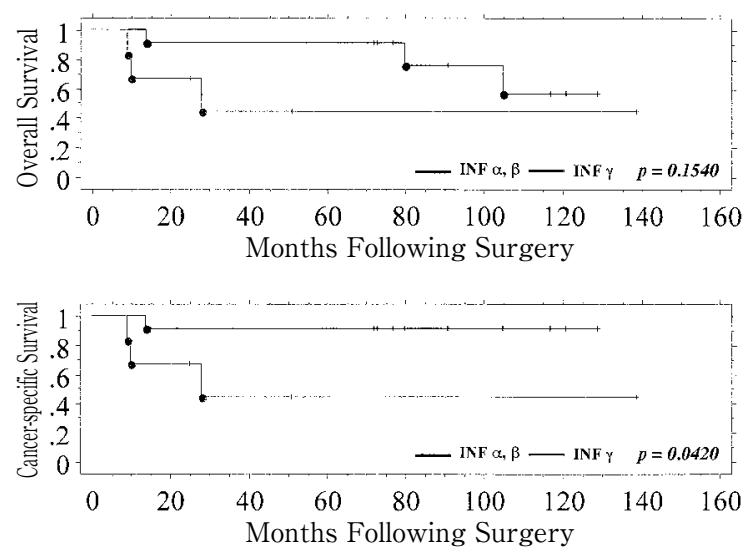

Fig. 3 Five and ten-year over all survival rates (upper) and cancer-specific survival rates (lower) stratified by infiltration pattern of the tumor cells between the alpha and beta group and gamma group.

$87.5 \%$ and $64.8 \%$, respectively, and the ten-year overall survival rates in the former and the latter were $87.5 \%$ and $34.6 \%$, respectively. The five and ten-year cancer-specific survival rates in the former and the latter were $87.5 \%$ and $64.8 \%$, respectively.

Significant prognostic factor associated with survival rates was only the infiltration pattern of the tumor cells between the alpha and beta group and gamma group $(\mathrm{P}=0.04)$ in cancer-specific survival rates. Both five and ten-year cancer-specific survival rates in the former group and the latter group were $90.9 \%$ and $44.4 \%$, respectively (Fig. 3).

\section{Discussion}

There were several reports concerning treatment with TUR for muscle-infiltrating carcinoma of the bladder, however, few dealt strictly with pT2a.

We intended to research only pT2a patients, however, it is apparent that expression of pT2a in TUR depends simply upon the diagnosis of the surgeon, and may include pT2b. Soloway mentioned in an editorial comment ${ }^{6}$ that "the separation of $\mathrm{T} 2$ classification into superficial and deep muscle invasion is controversial and not terribly accurate". We attempted to resect the entire or a piece of the tumor and the muscle together in one piece with deep bite whenever possible $e^{9,10}$. This technique in association with stepwise collection of muscle layer beneath the tumor as previously described enable accurate staging. In addition, one of the authors (G.K.) examined all specimens in present study and this likely attributed to accurate staging. Cases with pT2b may still have been included, however, cases with more superficial stages $\leqq$ pT1 were not included since we confirmed tumor cells in the muscle.

Table 3 shows the prognosis of pT2a patients treated by TURBT or cystectomy reported by several investigators. Five year survival rates varied from $62.5 \%$ to $76 \%$.

Solsona et al. $^{2}$ did not describe 5-year survival rates and only reported an overall survival rate of $83 \%$ with an average follow up of 55.4 months. In the present study, the overall survival rate upon follow up at 55.4 months was $76 \%$, however, the rate in patients who had TAI after initial TURBT was as high as $87.5 \%$.

Roosen et al. $^{8}$ reported only a median survival time of 19 months and it was much longer as 73 months in present study.

In another recent study of pT2a patients, Dalbagni et al. $^{12}$ reported a 5 -year survival rate of 17 patients with pathological stage pT2a treated by cystectomy was $62.57 \%$.

We believe the following are reasons for the favorable results in the present study: 1) The ability of the surgeon to resect the tumor and surrounding 
Table 3 Reported 5-year survival rates after transurethral resection for T2a muscle-infiltrating bladder cancer

\begin{tabular}{|c|c|c|c|c|}
\hline Reference & overall 5-year survival & disease specific 5 -year survival & BCG & TAI \\
\hline Herr $^{1}$ & $70 \quad(37)$ & ND & - & - \\
\hline Volkmer et al. ${ }^{6}$ & $69.1(22)$ & $94.1(22)$ & + & - \\
\hline Dalbagni et al. ${ }^{12}$ & $62.5(17)$ & ND & - & - \\
\hline Present study & $76.0(17)$ & 76.0 & $+* 1$ & $+* 2$ \\
\hline Solsona et $\mathrm{al}^{2}$ & \multirow{2}{*}{\multicolumn{2}{|c|}{$\begin{array}{l}\text { survival rate of } 83 \% \text { with an average followup of } 55.4 \text { months } \\
\text { median survival of } 19 \text { months in } 79 \text { patients }\end{array}$}} & - & - \\
\hline Roosen et al. $^{4}$ & & & - & - \\
\hline
\end{tabular}

The value shown are rates, with the number of patients in parentheses. BCG: Bacillus Calmette-Guerin, TAI: Transarterial Infusion of Anticancer Agents. ND: not described, * 1: performed in 15 of 17 patients. * 2: performed in 8 of 17 patients.

tissue adjacent to the fat so as not to leave any residual tumor, 2) Adjuvant therapy with BCG and TAI.

Brauers et $\mathrm{al}^{13}$ reviewed literature regarding residual tumors in second resection citing that $30 \%$ to $40 \%$ of the patients had residual tumors in second resection. The rate was $31 \%$ in 49 cases of Ta tumors. Therefore, the ability of the surgeon to resect all tumor cells is very important in avoiding recurrence. Brausi et al. ${ }^{14}$ also mentioned that the quality of TUR performed by individual surgeons may be responsible for a tumor recurrence.

Regarding intravesical instillation of BCG, Hara et al. ${ }^{15}$ recently reported that the risk of intravesical recurrence was significantly higher $(\mathrm{P}<0.01)$ for patients who did not receive adjuvant BCG therapy in their study of 97 patients with T1G3 TCC of the urinary bladder treated by TURBT with or without adjuvant BCG therapy. And Volkmer et al. ${ }^{6}$ recently reported on the value of intravesical instillation of BCG in patients with T2a shown in Table 3. Adjuvant BCG therapy is popular among superficial bladder cancer, however, use for muscle-infiltrating carcinoma is reasonable, especially if tumor cells are completely resected or remain only on surface of denuded muscle since mechanism of BCG therapy is falling off of remaining superficial layer of bladder tissue and immunological cytotoxicity triggered by recognition of tumor antigen by antigen presenting cells ${ }^{17}$.

Due to a small sample size, statistical difference between the prognosis of patients who had TAI after initial TURBT and that of patients who did not have TAI after initial TURBT was not obtained, however, there was a tendency for the prognosis of the former to be superior to that of the latter.

Usefulness of TAI in invasive bladder cancer including pT2aNOM0 TCC has been reported by several Japanese researchers ${ }^{15.16}$ and less side effect and higher concentration of anticancer agents in the bladder tissue compared to intravenous administration are the reason of usefulness of TAI.

In our institution, the department of radiology as well as our department developed a new system for isolated pelvic perfusion for advanced bladder cancer as well as gynecological cancer ${ }^{16}$, and we had favorable results in clinical trial. This treatment consists of transarterial infusion of anticancer agents and pelvic perfusion consists of occlusion of mid portion of inferior vena cava and abdominal artery in association of bilateral thigh tourniquets.

In deceased patients, the absence of TAI after initial TURBT and the ineffectiveness of anticancer agents to undetectable residual tumor in case 1 , and undetectable lymph node metastasis in Case 2 might be cause of poor prognosis, respectively. In cases 3 and 4, a tumor in the diverticulum and diffuse CIS might be the cause of poor prognosis, respectively.

In conclusion, our data support conservative management with transurethral resection followed by intravesical BCG and TAI in patients with pT2a muscle invasive transitional cell carcinoma of the bladder. 


\section{References}

1. Herr HW: Conservative management of muscleinfiltrating bladder cancer: prospective experience. J Urol 1987; 138: 1162-1163.

2. Solsona E, Iborra I, Ricos JV, Monros JL, Dumont R: Feasibility of transurethral resection for muscleinfiltrating carcinoma of the bladder: prospective study. J Urol 1992; 147: 1513-1515.

3. Ogawa $H$, Nishimura $T$, Hori $N$, Abe $H$, Ito $H$, Kubota M, Kiriyama I: 10-year survival rate in 92 patients with invasive bladder carcinoma treated by bladder sparing methods. J Nippon Med Sch 1997; 64: 446-454.

4. Roosen JU, Geertsen U, Jahn H, Weinreich J, Nissen HM: Invasive, high grade transitional cell carcinoma of the bladder treated with transurethral resection. A survival analysis focusing on TUR as monotherapy. Scan J Urol Nephrol 1997; 31: 39-42.

5. Herr HW, Bajorin DF, Scher HI: Neoadjuvant chemotherapy and bladder-sparing surgery for invasive bladder cancer: ten-year outcome. J Clin Oncol 1998; 16: 1298-1301.

6. Volkmer BG, Gschwend JU, Maier SH, Seidl-Schlick EM, Bach D, Romics I: T2a transitional cell carcinoma of the bladder: Longterm experience with intravesical immunoprophylaxis with bacillus Calmette-Guerin. J Urol 2003; 169: 931-935.

7. Tsujino S, Yamauchi T, Kokuho M, Kobayashi T, Tachibana Y, Sawano S, Kawaa T: Intra-arterial COMPA chemotherapy for invasive bladder cancer. Jap J Urol 1992; 83: 1640-1646.

8. Morita T, Kikuchi T, Ishikawa S, Kobayashi Y, Tozuka K, Goto K, Takahashi K, Yoshikawa K, Tanaka O, Tokue A: Intraarterial infusion chemotherapy with [sol Ile 8] angiotensin II to bladder cancer. Am J Clin Oncol 1992; 15: 188-193.

9. Nishimura T: Transurethral resection of bladder tumor. In: Urological endoscope: Technique and pitfall of diagnosis and treatment. Edited by $\mathrm{M}$. Akimoto. 1990; p 68, Igaku shoin, Tokyo.
10. Nishimura $\mathrm{T}$, Kondo $\mathrm{Y}$, Kimura Go, Miura $\mathrm{T}$, Uchikoba T, Abe H, Yoshida K: Factors affecting the quality of resection of muscle layer in transurethral resection of bladder tumor. Jpn J Endourol ESWL 2001; 14: 94-98.

11. Senga Y, Kimura G, Hattori T, Yoshida K: Clinical evaluation of soluble cytokeratin 19 fragments (CYFRA 21-1) in serum and urine of patients with bladder cancer: Urol 1996; 48: 703-710.

12. Dalbagni G, Genecga E, Hashibe M, Zhang Z, Russo P, Herr H, Reuter V: Cystectomy for bladder cancer: A contemporary series. J Urol 2001; 165: 1111-1116.

13. Brauers A, Buettner R, Jakse G: Second resection and prognosis of primary high risk superficial bladder cancer: Is cystectomy often too early? J Urol 2001; 165: 808-810.

14. Brausi M, Collette L, Kurth K, van der Meijden AP, Oosterlinck W, Witjes JA, Newling D, Boouffioux C, Sylvester RJ, EORTC Genito-Urinary Tract Cancer Collaborative Group: Variability in the recurrence rate at first follow-up cystoscopy after TUR in stage Ta T1 transitional cell carcinoma of the bladder: A combined analysis of seven EORTC studies. Eur Urol 2002; 41: 523-531.

15. Hara I, Miyake H, Takechi Y, Eto H, Gotoh A, Fujisawa M, Okada H, Arakawa S, Kamidono S, Kobe Urogenital Tumor Study Group: Clinical outcome of conservative therapy for stage T1, grade 3 transitional cell carcinoma of the bladder. Int $\mathrm{J}$ Urol 2003; 10: 19-24.

16. Kimata R, Kondo Y, Shioji T, Kimura G, Horiuchi K, Tsuboi N, Nishimura T, Murata S, Tajima H, Kumazaki T: Round table discussion 12. Development and clinical application of a new system for isolated pelvic perfusion in invasive bladder cancer. J Jpn Soc Cancer Ther 2001; 36: 468.

17. Soloway MS, Sofer M, Vaidya A:Contemporary management of stage $\mathrm{T} 1$ transitional cell carcinoma of the bladder. J Urol 2002; 167: 1573-1583.

(Received, January 26, 2004)

(Accepted, March 23, 2004) 